Vincent Koppelmans and Monique M.B. Breteler, Erasmus MC University Medical Center; Caroline Seynaeve, Erasmus MC University Medical Center, Daniel den Hoed Cancer Center, Rotterdam; Vincent Koppelmans, Willem Boogerd, Chad Gundy, and Sanne B. Schagen, Netherlands Cancer Institute/Antoni van Leeuwenhoek Hospital, Amsterdam, the Netherlands; Monique M.B. Breteler, German Center for Neurodegenerative Diseases; and Monique M.B. Breteler, University Bonn, Bonn, Germany

tDeceased

Submitted May 11, 2011; accepted December 7, 2011; published online ahead of print at www.jco.org on February 27, 2012

M.M.B.B. and S.B.S. contributed equally to this article.

Authors' disclosures of potential conflicts of interest and author contributions are found at the end of this article.

Corresponding author: Sanne B. Schagen, PhD, Netherlands Cancer Institute/Antoni van Leeuwenhoek Hospital, Plesmanlaan 121, Amsterdam the Netherlands 1066 CX; e-mail: s.schagen@nki.nl.

(C) 2012 by American Society of Clinical Oncology

0732-183X/12/3010-1080/\$20.00

DOI: 10.1200/JCO.2011.37.0189

\title{
Neuropsychological Performance in Survivors of Breast Cancer More Than 20 Years After Adjuvant Chemotherapy
}

Vincent Koppelmans, Monique M.B. Breteler, Willem Boogerd, Caroline Seynaeve, Chad Gundy, $\dagger$ and Sanne B. Schagen

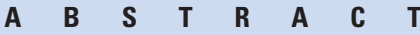

\section{Purpose}

Adjuvant chemotherapy for breast cancer can have adverse effects on cognition shortly after administration. Whether chemotherapy has any long-term effects on cognition is largely unknown, yet it becomes increasingly relevant because of the widespread use of chemotherapy for early-stage breast cancer and the improved survival. We investigated whether cyclophosphamide, methotrexate, and fluorouracil (CMF) chemotherapy for breast cancer is associated with worse cognitive performance more than 20 years after treatment.

\section{Patients and Methods}

This case-cohort study compared the cognitive performance of patients with breast cancer who had a history of adjuvant CMF chemotherapy treatment (six cycles; average time since treatment, 21 years; $n=196$ ) to that of a population-based sample of women never diagnosed with cancer ( $n=1,509$ ). Participants were between 50 and 80 years of age. Exclusion criteria were ever use of adjuvant endocrine therapy, secondary malignancy, recurrence, and/or metastasis.

\section{Results}

The women exposed to chemotherapy performed significantly worse than the reference group on cognitive tests of immediate $(P=.015)$ and delayed verbal memory $(P=.002)$, processing speed $(P<.001)$, executive functioning $(P=.013)$, and psychomotor speed $(P=.001)$. They experienced fewer symptoms of depression $(P<.001)$, yet had significantly more memory complaints on two of three measures that could not be explained by cognitive test performance.

\section{Conclusion}

Survivors of breast cancer treated with adjuvant CMF chemotherapy more than 20 years ago perform worse, on average, than random population controls on neuropsychological tests. The pattern of cognitive problems is largely similar to that observed in patients shortly after cessation of chemotherapy. This study suggests that cognitive deficits following breast cancer diagnosis and subsequent CMF chemotherapy can be long lasting.

\section{J Clin Oncol 30:1080-1086. (C) 2012 by American Society of Clinical Oncology}

\section{INTRODUCTION}

Chemotherapy has well-recognized acute adverse effects, including nausea and hair loss. Cognitive impairment is a potential short-term adverse effect that has gained more attention only in the last decade. ${ }^{1-20}$ Several studies have shown that chemotherapy can induce cognitive changes up to 5 years after treatment. ${ }^{2,5,14,20}$ Differences are primarily observed in the domains of memory, processing speed, and executive function and are generally not explained by sociodemographic and clinical variables. ${ }^{21}$ Nevertheless, cognitive dysfunction has also been observed in the domains of visuospatial functioning ${ }^{22}$ and psychomotor speed. ${ }^{15}$ Potential predictors for cognitive problems, such as cognitive reserve and genetic susceptibility, in patients with breast cancer who have been exposed to chemotherapy are topics of ongoing research. ${ }^{23}$ Besides differences in cognitive performance, structural brain differences have been observed in patients who underwent chemotherapy compared with controls, including more white-matter hyperintensities, microstructural damage to white-matter tracts, and gray matter alterations, ${ }^{1,7,24-30}$ whereas functional magnetic resonance imaging (fMRI) studies revealed measurable differences in task-specific responsiveness between patients exposed to chemotherapy and controls. ${ }^{5,26,31}$ The observational studies in humans are strongly supported by animal studies. ${ }^{32}$

Whether chemotherapy has long-term effects on brain function is still largely unknown. However, 
this question is becoming increasingly relevant because the number of long-term survivors is rapidly increasing.

We investigated the late effects of chemotherapy on cognitive functioning by comparing the neuropsychological test performance of women with breast cancer who received adjuvant cyclophosphamide, methotrexate, and fluorouracil (CMF) chemotherapy on average more than 20 years before that of a population sample of women who had never been diagnosed with cancer.

\section{PATIENTS AND METHODS}

\section{Participants}

Our case group consisted of survivors of breast cancer who had undergone adjuvant chemotherapy in either of two specialized cancer clinics in the Netherlands. The reference group of controls was selected from an ongoing population study in the Netherlands. The review boards of the participating institutes (the Netherlands Cancer Institute/Antoni van Leeuwenhoek Hospital and the Erasmus University Medical Center) approved this study.

\section{Patients Exposed to Chemotherapy}

From the registries of the Netherlands Cancer Institute/Antoni van Leeuwenhoek Hospital and the Erasmus University Medical Center-Daniel den Hoed Cancer Center, we identified consecutive female patients with breast cancer who, as part of their primary treatment had received six cycles of adjuvant CMF chemotherapy (cyclophosphamide $100 \mathrm{mg} / \mathrm{m}^{2}$ orally on days 1 through 14 , methotrexate $40 \mathrm{mg} / \mathrm{m}^{2}$ intravenously on days 1 and 8 , and fluorouracil $600 \mathrm{mg} / \mathrm{m}^{2}$ intravenously on days 1 and 8) between 1976 and 1995. Eligibility criteria included age between 50 and 80 years at recruitment in 2008 and sufficient command of the Dutch language. Only those women who never had a relapse, secondary primary tumor, or distant metastasis were selected. Exclusion criteria were ever use of adjuvant endocrine therapy and contraindications for MRI.

Potential participants $(\mathrm{n}=359)$ were sent an invitation letter and information on the study. Twenty patients $(5.6 \%)$ could not be reached either because their current address was unavailable, or they did not respond to the invitation or subsequent reminders. Fifteen patients (4.2\%) had a healthrelated contraindication for MRI, 30 (8.4\%) were ineligible for MRI assessment because of claustrophobia, and two patients $(0.6 \%)$ had insufficient command of the Dutch language. The final number of eligible patients was 292 of whom 196 (67.1\%) eventually agreed to participate and provided written informed consent. Examinations were performed between October 2008 and October 2009.

Main reasons for decline were not wanting to be reminded of the cancer episode (21.9\%) and unwillingness to undergo MRI assessment (26.0\%). Decliners were older than participants $\left(F_{1,290}=12.24 ; P=.001\right)$.

To assess possible selection bias, eligible women who declined participation and women for whom claustrophobia was the only contraindication were invited to complete the interview and the neuropsychological assessments at home. Test results of these initial decliners were compared with the results of those who participated in this study. Of the 126 invited initial decliners (96 decliners +30 claustrophobic women), 48 (38.1\%) agreed to participate. They were assessed between November 2009 and June 2010.

\section{Reference Group}

A reference group was selected from the Rotterdam Study, ${ }^{33}$ a population-based prospective cohort study ongoing since 1990 in Rotterdam, the Netherlands. By the end of 2008, 14,926 participants had been included in three separate subcohorts. Rotterdam Study III is the most recent subcohort, comprising 3,932 persons who have been assessed only once between February 2006 and December 2008. To date, it is the only cohort that has been assessed with an extensive set of neuropsychological tests and is therefore the most appropriate reference subcohort.

From Rotterdam Study III, we selected all women without a history of cancer on the basis of self-reports and linkage with data from their general physician, who were between 50 and 80 years of age at the time of neuropsychological assessment. In total, 1,509 participants met these criteria.

\section{Methods}

Examination of the participants took place at the Rotterdam Study research center. ${ }^{34}$ Participants underwent neuropsychological examinations and an interview identical with those used in the Rotterdam Study. Subsequently, blood was drawn, height and weight were measured, and participants underwent MRI of the brain, carotid ultrasound imaging, and an electrocardiogram. Results from the latter measures will be described separately.

\section{Neuropsychological Examination}

Seven neuropsychological tests were administrated and scored by experienced test assistants from the Rotterdam Study. These tests yielded 17 outcomes in the following cognitive domains: processing speed, verbal learning, memory, inhibition and word fluency as elements of executive functioning, visuospatial ability, and psychomotor speed. In addition, the Mini-Mental State Examination (MMSE) was included as a dementia screener. For an overview of the tests and domains, ${ }^{35-42}$ see Table 1.

\section{Interview}

Participants completed an interview on clinical and sociodemographic factors, which included questions regarding medical history of neurologic, psychiatric, and cardiovascular diseases. Depressive symptoms were assessed with the Center for Epidemiologic Studies Depression scale (CES-D), ${ }^{43}$ which was converted to a sum-score according to the standard scoring rules. ${ }^{44}$ Subjective memory complaints were measured with three yes/no questions: (1) Do you have more problems remembering things than before? (2) Has there been an increase in the times that you forgot what you were up to? and (3) Do you have more word-finding problems than before? Subsequently, participants were asked whether these problems had an acute onset (yes/no) and if the severity of the problems had changed over time (no change/problems increased/problems decreased).

\section{Statistical Analysis}

We compared differences in sociodemographic variables between groups by means of binary, ordinal, and multinomial logistic regression analysis. Group differences in neuropsychological performance and depressive symptoms were investigated with analysis of covariance, adjusted for age and education. Although studies on the cognitive effects of chemotherapy shortly after treatment do not show a strong relationship between depressive symptoms and neuropsychological performance, ${ }^{45}$ no information is available on this potential association long after chemotherapy. Therefore, we subsequently adjusted our analyses for CES-D sum-score. We used Bonferroni correction to account for multiple testing.

The age distribution of the reference group was more skewed toward younger ages than that of the survivors of cancer exposed to chemotherapy. To check whether any residual confounding by age remained after standard adjustment for age, we executed all analyses with propensity scores for age and used an age-matched reference group randomly drawn from the total reference group. Since these additional analyses yielded results similar to those of the primary analyses, their results are not separately reported.

Although the different cognitive tests in our battery were intended to measure different domains, an individual's scores on cognitive tests were often related. To account for this interdependency between test scores, we calculated for each individual the Mahalanobis Distance $(\mathrm{MD})^{46}$ as a summary measure of overall performance. ${ }^{47}$ The MD takes into account the correlations between test scores and the different variances of the test scores and can be interpreted as the distance to the mean of the multidimensional distribution of the neuropsychological test scores of the reference group.

MD was based on all tests, except for the Design Organization test because few women from the reference group completed this test and the MMSE because it screens for dementia. We calculated age, education, and CES-D score-adjusted residuals of the neuropsychological tests, although the computation of the relevant means and (co)variances was based on the residuals of the reference group. ${ }^{47,48}$ We assigned a value of zero to all residual scores that were greater than their respective mean score from the reference group, such that positive test scores could not compensate for negative 


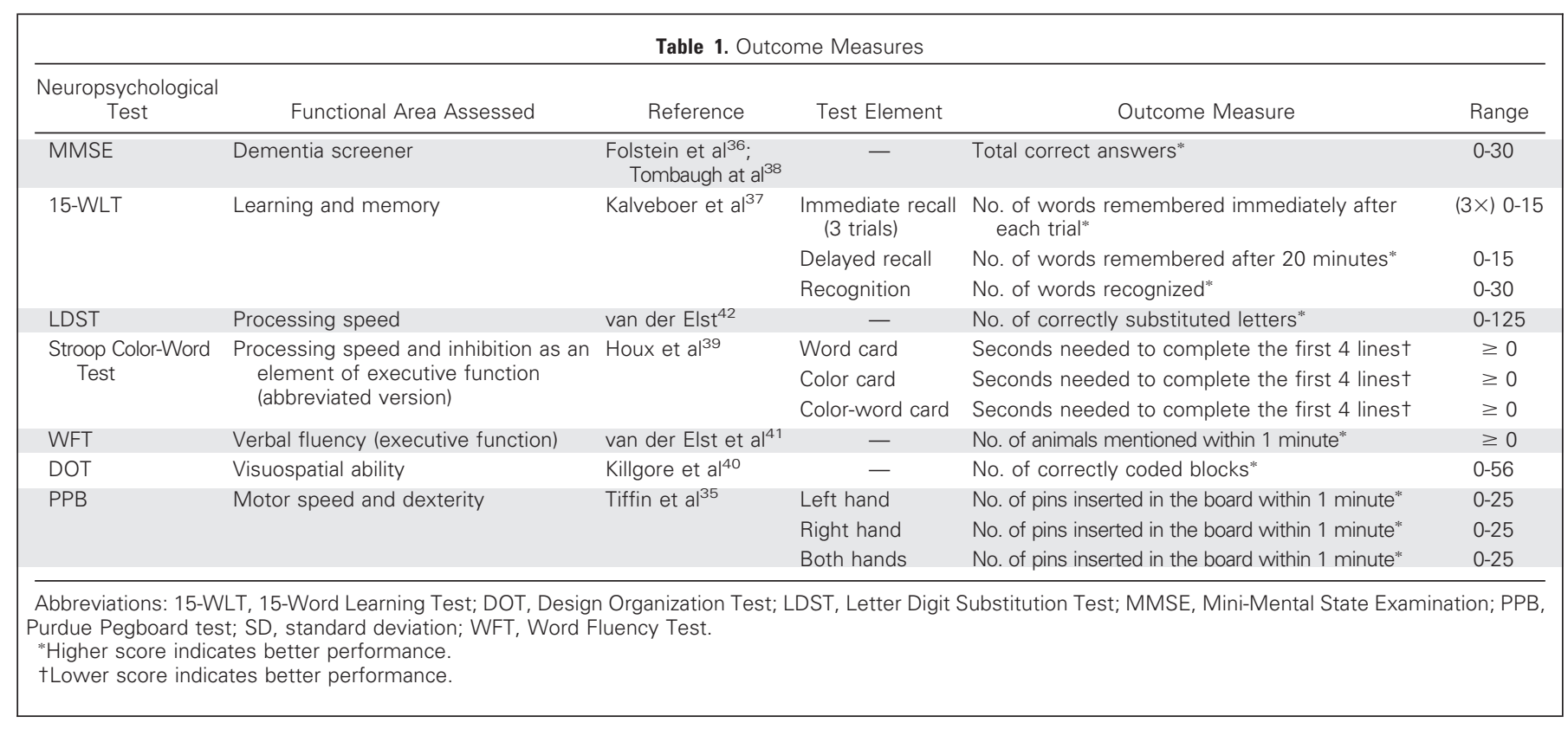

scores. ${ }^{49}$ We transformed the MD with log base 2 because of skewness of its distribution and subsequently used one-way analysis of variance to compare MD between the patients exposed to chemotherapy and the reference group.

Spearman rank correlation coefficients with two-sided $P$ values were calculated to obtain the associations between memory complaints, neuropsychological test outcomes, and mood. For all analyses, $\alpha$ levels were set at $P=.05$.

\section{RESULTS}

Table 2 presents the baseline characteristics of the patients with breast cancer who were exposed to chemotherapy and the reference group. On average, survivors of breast cancer were older and had completed a

Table 2. Sociodemographic and Clinical Characteristics of Former Patients With Breast Cancer Exposed to Chemotherapy and the Reference Group From the General Population

\begin{tabular}{|c|c|c|c|c|c|c|c|}
\hline \multirow[b]{2}{*}{ Characteristic } & \multicolumn{3}{|c|}{$\begin{array}{l}\text { Patients Exposed } \\
\text { to Chemotherapy } \\
\quad(n=196)\end{array}$} & \multicolumn{3}{|c|}{$\begin{array}{l}\text { Reference Group } \\
\quad(n=1,509)\end{array}$} & \multirow[b]{2}{*}{$P$} \\
\hline & $\%$ & Mean & SD & $\%$ & Mean & SD & \\
\hline Age, years & & 64.1 & 6.4 & & 57.9 & 5.4 & $<.001$ \\
\hline Education level & & & & & & & $<.001$ \\
\hline Primary & 8.7 & & & 12.5 & & & \\
\hline Lower vocational & 16.3 & & & 21.5 & & & \\
\hline Intermediate general & 20.4 & & & 24.2 & & & \\
\hline Intermediate vocational & 16.8 & & & 16.3 & & & \\
\hline Higher general & 5.6 & & & 5.2 & & & \\
\hline College & 23.5 & & & 16.1 & & & \\
\hline University & 8.7 & & & 4.2 & & & \\
\hline $\begin{array}{c}\text { Age at breast cancer } \\
\text { diagnosis, years }\end{array}$ & & 42.9 & 5.3 & & & & \\
\hline $\begin{array}{c}\text { Time since breast cancer } \\
\text { diagnosis, years }\end{array}$ & & 21.2 & 4.4 & & & & \\
\hline
\end{tabular}

Abbreviation: SD, standard deviation. higher level of education. They had been diagnosed, on average, at age 42.9 and received chemotherapy, on average, 21.2 years before enrollment onto this study. No differences were observed in the prevalence of neurologic, psychiatric, or cardiovascular diseases.

\section{Neuropsychological Outcomes}

On all neuropsychological tests, survivors of breast cancer who had been exposed to chemotherapy performed similar to or worse than those in the reference group. These differences were significant for nearly all trials of immediate and delayed recall of the 15-Word Learning Test (15-WLT), for the color card and the color-word card of the Stroop test, and for nondominant-hand performance on the Purdue pegboard test (Table 3; Fig 1). After Bonferroni corrections, differences on the 15-WLT delayed recall, the Stroop color card, and the Purdue pegboard test for the nondominant-hand condition remained significant. MMSE scores did not differ between groups. Excluding participants with neurologic or psychiatric diseases did not change the outcome of the analyses.

The log base 2 of the MD was significantly larger for survivors exposed to chemotherapy (mean, 2.8; standard deviation [SD], 2.6) than for the reference group (mean, $2.2 ; \mathrm{SD}, 2.8 ; F_{1,1648}, 7.3 ; P=.007$ ), indicating that the former had worse overall cognitive performance. Time since diagnosis was not associated with neuropsychological performance in survivors exposed to chemotherapy.

\section{Depressive Symptoms and Memory Complaints}

The reference group reported significantly more depressive symptoms than the survivors of breast cancer exposed to chemotherapy (age-adjusted mean sum-score of the reference group on the CES-D, 6.7; SD, 8.4; age-adjusted mean sum-score of the chemotherapy-exposed survivors on the CES-D, 4.7; SD, 8.0; $\left.F_{1,1696}, 9.54 ; P=.002\right)$. There was a low correlation between memory complaints and total score on the CES-D $(\rho=.275$; $P<.001)$ in survivors exposed to chemotherapy. 


\begin{tabular}{|c|c|c|c|c|c|c|c|}
\hline \multirow[b]{2}{*}{ Test Outcome } & \multicolumn{3}{|c|}{$\begin{array}{l}\text { Patients With Breast } \\
\text { Cancer Exposed to } \\
\text { Chemotherapy } \\
(n=196)\end{array}$} & \multicolumn{3}{|c|}{$\begin{array}{l}\text { Reference Group } \\
\quad(\mathrm{n}=1,518)\end{array}$} & \multirow[b]{2}{*}{$P$} \\
\hline & No. & Mean & SD & No. & Mean & SD & \\
\hline$\overline{\mathrm{MMSE}}$ & 196 & 28.4 & 2.0 & 1,507 & 28.2 & 2.2 & .09 \\
\hline 15-WLT: trial 1 & 194 & 5.5 & 2.2 & 1,397 & 5.9 & 2.4 & .008 \\
\hline 15-WLT: trial 2 & 194 & 8.6 & 2.4 & 1,397 & 9.0 & 2.7 & .02 \\
\hline 15-WLT: trial 3 & 194 & 10.3 & 2.6 & 1,397 & 10.6 & 2.9 & .17 \\
\hline 15-WLT: total of 3 trials & 194 & 24.3 & 6.2 & 1,397 & 25.5 & 6.9 & .02 \\
\hline 15-WLT: delayed recall & 194 & 8.0 & 2.9 & 1,397 & 8.7 & 3.2 & .002 \\
\hline 15-WLT: recognition & 194 & 13.8 & 1.8 & 1,397 & 13.8 & 2.0 & .76 \\
\hline LDST: total correct & 195 & 31.8 & 6.7 & 1,497 & 32.5 & 7.5 & .14 \\
\hline Stroop: word card & 195 & 16.8 & 3.3 & 1,404 & 16.5 & 3.7 & .14 \\
\hline Stroop: color card & 195 & 23.3 & 4.4 & 1,404 & 22.2 & 4.9 & .001 \\
\hline Stroop: color-word card & 195 & 45.8 & 12.6 & 1,404 & 43.5 & 14.0 & .02 \\
\hline Word fluency: total & 194 & 24.1 & 6.1 & 1,490 & 24.2 & 6.8 & .89 \\
\hline $\begin{array}{l}\text { Word fluency: after } 15 \\
\text { seconds }\end{array}$ & 194 & 13.8 & 4.8 & 1,490 & 13.8 & 5.4 & .95 \\
\hline DOT: total correct & 195 & 28.9 & 9.2 & 511 & 28.9 & 9.7 & .99 \\
\hline PPB: both hands & 195 & 11.1 & 1.6 & 1,494 & 11.2 & 1.8 & .56 \\
\hline PPB: dominant hand & 195 & 13.8 & 1.9 & 1,490 & 13.8 & 2.1 & .81 \\
\hline PPB: nondominant hand & 195 & 12.9 & 1.8 & 1,490 & 13.4 & 2.0 & .001 \\
\hline \multicolumn{8}{|c|}{$\begin{array}{l}\text { Abbreviations: } 15-W L T, 15-\text { Word Learning Test; DOT, Design Organization } \\
\text { Test; LDST, Letter Digit Substitution Test; MMSE, Mini-Mental State Exami } \\
\text { nation; PPB, Purdue Pegboard test; SD, standard deviation. }\end{array}$} \\
\hline
\end{tabular}

The proportion of patients who reported problems with remembering did not differ between groups, yet survivors of breast cancer who were exposed to chemotherapy were more likely to report an increase in word-finding problems and in the frequency of forgetting pursuits (Table 4). These subjective memory complaints were not related to neuropsychological performance.

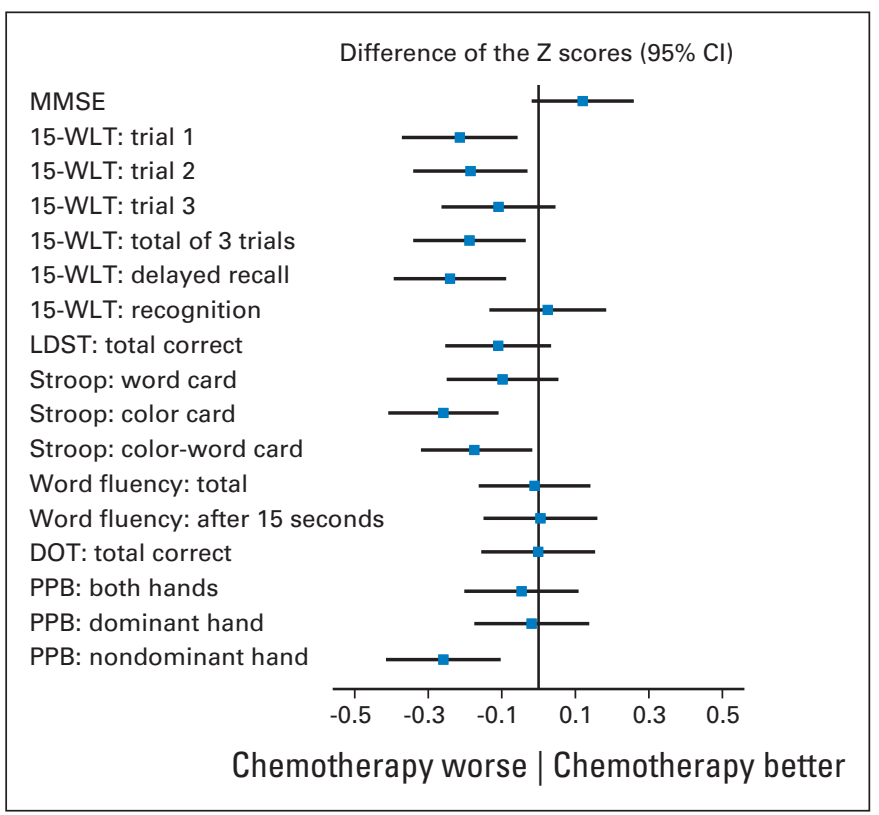

Fig 1. Difference between standardized ( $Z$ ) scores of the chemotherapyexposed survivors of breast cancer and reference subjects. 15-WLT, 15-Word Learning Test; DOT, Design Organization Test; LDST, Letter Digit Substitution Test; MMSE, Mini-Mental State Examination; PPB, Purdue Pegboard test.
Survivors of breast cancer exposed to chemotherapy who participated at the Rotterdam Study research center did not differ from participants who declined participation at the research center but agreed to cognitive testing in their own home regarding age, education level, Bonferroni-corrected cognitive scores, or mood status. Without correction for multiple testing, home participants performed worse than center participants on one of the 17 cognitive measures: the word card of the Stroop test $(P=.011)$.

\section{DISCUSSION}

To the best of our knowledge, this is the first report on the cognitive effects of adjuvant CMF chemotherapy in survivors of breast cancer who completed their treatment, on average, more than 21 years before. Compared with women from the general population without cancer, survivors of breast cancer who were exposed to chemotherapy performed worse on cognitive tests covering the domains of learning, immediate and delayed verbal memory, information processing speed, inhibition, and psychomotor speed. No differences were observed in scores on a dementia screener. The results persisted after controlling for several confounders including age, education level, and depression score. After subsequent correction for multiple comparisons, survivors exposed to chemotherapy still performed worse on tests measuring delayed verbal memory, processing speed, and psychomotor speed. In addition, on a summary measure of the neuropsychological tests that takes correlations between multiple measures into account, survivors exposed to chemotherapy performed significantly worse than women from the general population.

Further, survivors of breast cancer exposed to chemotherapy more often reported memory complaints, which were not associated with test performance but were weakly correlated with mood. Survivors exposed to chemotherapy had fewer depressive symptoms than the reference group, although both groups scored below the cutoff score of 16 , which is indicative for clinical depression. ${ }^{43}$

Strengths of our study are the large sample size, the long interval since chemotherapy, the homogeneous study population regarding cytotoxic agents (regimen, cycles), and the large population-based reference group without cancer. Possible selection bias within the chemotherapy-exposed group has been investigated and was found to be unlikely.

We compared chemotherapy-exposed survivors of breast cancer to a population-based sample of healthy controls without a history of cancer because we wanted to investigate to what extent chemotherapy-exposed survivors of breast cancer deviate from the norm regarding cognitive functioning. Subsequently, because tamoxifen was not part of standard treatment in the Netherlands until the mid 1990s, it was not possible to include a comparison group of long-term tamoxifen-exposed survivors. Because of our design, we were unable to distinguish the effect of chemotherapy on cognition from the possible effect of breast cancer itself.

It has been suggested that patients with breast cancer may already perform worse on tests of cognitive function compared with healthy controls before the start of chemotherapy..$^{8-10,15,18,50,51}$ Since we do not have pretreatment assessments to use for adjusting our results, our findings might partially reflect group differences already present before chemotherapy. The mechanisms for pretreatment differences are 
Table 4. Subjective Cognitive Complaints in Patients With Breast Cancer Exposed to Chemotherapy and in a Reference Group From the General Population

\begin{tabular}{|c|c|c|c|c|c|c|}
\hline Memory Complaints & Exact Question & $\begin{array}{l}\text { Patients Exposed to } \\
\text { Chemotherapy }(\%)^{*}\end{array}$ & $\begin{array}{l}\text { Reference } \\
\text { Group }(\%)^{* *}\end{array}$ & OR & $95 \% \mathrm{Cl}^{*}$ & $P$ \\
\hline More problems remembering & $\begin{array}{l}\text { Do you have more problems remembering things } \\
\text { than before? }\end{array}$ & 52.8 & 46.1 & 1.32 & 0.96 to 1.82 & .09 \\
\hline Forgetting (daily) pursuits & $\begin{array}{l}\text { Has there been an increase in the times that you } \\
\text { forgot what you were up to? }\end{array}$ & 42.9 & 35.2 & 1.41 & 1.01 to 1.96 & .042 \\
\hline Word-finding problems & $\begin{array}{l}\text { Do you have more word-finding problems than } \\
\text { before? }\end{array}$ & 38.2 & 30.2 & 1.46 & 1.04 to 2.05 & .030 \\
\hline Rapid onset of problems & Did the problems occur suddenly? & 10.7 & 13.4 & 0.76 & 0.36 to 1.62 & .48 \\
\hline Change in problems & Have the problems changed over time? & & & & & \\
\hline Worsened over time & Referencet & 30.5 & 19.6 & 1.68 & 0.99 to 2.82 & .05 \\
\hline Improved over time & Referencet & 5.8 & 6.5 & 0.98 & 0.36 to 2.65 & .97 \\
\hline
\end{tabular}

Abbreviations: CES-D, Center for Epidemiologic Studies Depression scale; OR, odds ratio.

*Depression score (CES-D) and age adjusted.

†No change over time.

largely unknown, although the prevalence of cognitive problems at baseline has been associated with the stage of breast cancer. ${ }^{51}$ Suggested explanations for pretreatment problems include diminished cognitive reserve, stimulation of proinflammatory cytokines, ${ }^{18}$ and the effect of anesthetic drugs received for breast surgery. ${ }^{52}$ Because the effect of anesthesia is transient, ${ }^{52}$ we consider its influence on cognition more than 20 years post treatment unlikely. Moreover, follow-up studies demonstrated a larger prevalence of cognitive decline from baseline in chemotherapy-exposed patients than in patients who underwent only locoregional therapy, indicating that at least part of the deficits are indeed associated with cytotoxic treatment. ${ }^{3,15,53-56}$

Although information on hormone replacement therapy was not available, we do not think this confounded our findings in any significant way because the use of hormone replacement therapy in the Netherlands tended to be low in the years under study $(<2.5 \%$ of women age 40 to 74 years). ${ }^{57}$

An important question is to what extent our observations extend to other chemotherapy regimens. The CMF regimen is no longer the most optimal adjuvant chemotherapy for early-stage breast cancer. However, it was the standard regimen up to the 1990s, and it is the only regimen that enables the investigation of the late effects of chemotherapy in sufficiently large numbers of patients. In addition, there is still an extensive group of women who have been treated with CMF in the late 1990s, some of whom may experience its cognitive adverse effects in the future. Furthermore, cyclophosphamide and fluorouracil continue to be incorporated into currently used regimens for early-stage breast cancer. Even if the findings of our study were specific to CMF, they would remain relevant.

Several studies have found impairments in cognitive domains in patients with cancer shortly after treatment with chemotherapy., 58-65 Impairments frequently observed in chemotherapy-exposed patients with breast cancer are learning problems and deficits in memory retrieval with more preserved retention, as well as problems with information processing speed and more complex aspects of attention. Imaging studies showed that some chemotherapy regimens may induce structural brain alterations. ${ }^{1,7,24,25,27,28}$

This study resembles this pattern: chemotherapy-exposed survivors of breast cancer from our study also had more problems with learning and memory retrieval although retention was intact. The combination of worse processing speed, inhibition problems, and problems with fine motor functioning that we observed in chemotherapy-exposed survivors adds to this profile. This profile is suggestive for disruption of the frontal-subcortical network and matches the profile observed in other studies. ${ }^{65}$

The fact that chemotherapy-exposed survivors of breast cancer performed worse on the nondominant condition of the Purdue pegboard test, but not on the dominant condition, has been observed before in patients treated with chemotherapy ${ }^{7}$ and other patient populations. It has been related to neurologic damage ${ }^{66}$ and may possibly be related to interhemispheric transfer deficits. ${ }^{67}$

Our neuropsychological test battery was identical with the one used in the Rotterdam Study but less extensive than some used in previous studies. ${ }^{15,22,54,68,69}$ Some domains (eg, visual memory), which are known to be affected by cytotoxic treatment, were not explicitly examined. ${ }^{15,22,70}$ Although we found several significant differences in cognitive functioning between chemotherapy-exposed survivors and the reference group, we may have underestimated the effects of CMF chemotherapy on cognitive functioning. The effects of chemotherapy might extend to more cognitive domains than we showed in this study.

When we compare our study outcomes with those of other studies investigating the cognitive effects of CMF chemotherapy, there are several similarities. One study ${ }^{20}$ showed that patients who underwent $\mathrm{CMF}$ at least 10 years ago performed worse than healthy controls on tests measuring executive functioning, psychomotor speed, and attention. Another study ${ }^{71}$ found that a subgroup of patients treated with CMF showed impaired information processing speed 5 years after completion of treatment. Animal studies support our findings and have pointed out that methotrexate, cyclophosphamide, and the combination of fluorouracil and methotrexate are associated with impaired learning and memory and structural brain changes. ${ }^{32,72-76}$

In conclusion, the cognitive functioning of survivors of breast cancer on average 21 years after adjuvant CMF chemotherapy is worse than that of women from the general population who have never been diagnosed with cancer. These data suggest that cognitive deficits following breast cancer diagnosis and subsequent CMF chemotherapy are at least partially long lasting. Our results are highly relevant in the field of survivorship because, with the current treatment strategies, the number of long-term survivors of breast cancer is increasing because of improved recognition of early-stage 
breast cancer, aging of the population, and improved survival after breast cancer diagnosis. ${ }^{77,78}$ Further studies into the late effects of adjuvant chemotherapy for cancer are needed to corroborate these results and to gain further insight into the mechanisms underlying these observations.

\section{AUTHORS' DISCLOSURES OF POTENTIAL CONFLICTS OF INTEREST}

The author(s) indicated no potential conflicts of interest.

\section{AUTHOR CONTRIBUTIONS}

Conception and design: Monique M.B. Breteler, Sanne B. Schagen

Financial support: Monique M.B. Breteler, Sanne B. Schagen

Provision of study materials or patients: Willem Boogerd,

Caroline Seynaeve

Collection and assembly of data: Vincent Koppelmans

Data analysis and interpretation: All authors

Manuscript writing: All authors

Final approval of manuscript: All authors

\section{REFERENCES}

1. Abraham J, Haut MW, Moran MT, et al: Adjuvant chemotherapy for breast cancer: Effects on cerebral white matter seen in diffusion tensor imaging. Clin Breast Cancer 8:88-91, 2008

2. Ahles TA, Saykin AJ, Furstenberg CT, et al: Neuropsychologic impact of standard-dose systemic chemotherapy in long-term survivors of breast cancer and lymphoma. J Clin Oncol 20:485-493, 2002

3. Ahles TA, Saykin AJ, McDonald BC, et al: Longitudinal assessment of cognitive changes associated with adjuvant treatment for breast cancer: impact of age and cognitive reserve. J Clin Oncol 28:4434-4440, 2010

4. Castellon SA, Silverman DH, Ganz PA: Breast cancer treatment and cognitive functioning: current status and future challenges in assessment. Breast Cancer Res Treat 92:199-206, 2005

5. de Ruiter MB, Reneman L, Boogerd W, et al: Cerebral hyporesponsiveness and cognitive impairment 10 years after chemotherapy for breast cancer. Human Brain Mapping 32:1206-1219, 2011

6. Debess J, Riis JØ, Engebjerg MC, et al: Cognitive function after adjuvant treatment for early breast cancer: a population-based longitudinal study. Breast Cancer Res Treat 121:91-100, 2010

7. Deprez S, Amant F, Yigit R, et al: Chemotherapyinduced structural changes in cerebral white matter and its correlation with impaired cognitive functioning in breast cancer patients. Hum Brain Mapp 32:480-493, 2011

8. Hermelink K, Untch M, Lux MP, et al: Cognitive function during neoadjuvant chemotherapy for breast cancer: results of a prospective, multicenter, longitudinal study. Cancer 109:1905-1913, 2007

9. Jansen $C E$, Cooper BA, Dodd MJ, et al: A prospective longitudinal study of chemotherapyinduced cognitive changes in breast cancer patients. Support Care Cancer 19:1647-1656, 2011

10. Jansen CE, Dodd MJ, Miaskowski CA, et al: Preliminary results of a longitudinal study of changes in cognitive function in breast cancer patients undergoing chemotherapy with doxorubicin and cyclophosphamide. Psychooncology 17:1189-1195, 2008

11. Jim HS, Donovan KA, Small BJ, et al: Cognitive functioning in breast cancer survivors: a controlled comparison. Cancer 115:1776-1783, 2009

12. Reid-Arndt SA, Hsieh C, Perry MC: Neuropsychological functioning and quality of life during the first year after completing chemotherapy for breast cancer. Psychooncology 19:535-544, 2010

13. Schagen SB, Muller MJ, Boogerd $W$, et al: Change in cognitive function after chemotherapy: $A$ prospective longitudinal study in breast cancer patients. J Natl Cancer Inst 98:1742-1745, 2006
14. Scherwath A, Mehnert A, Schleimer B, et al: Neuropsychological function in high-risk breast cancer survivors after stem-cell supported high-dose therapy versus standard-dose chemotherapy: evaluation of long-term treatment effects. Ann Oncol 17:415-423, 2006

15. Tager FA, McKinley PS, Schnabel FR, et al: The cognitive effects of chemotherapy in postmenopausal breast cancer patients: a controlled longitudinal study. Breast Cancer Res Treat 123:2534, 2010

16. van Dam FS, Schagen SB, Muller MJ, et al: Impairment of cognitive function in women receiving adjuvant treatment for high-risk breast cancer: High-dose versus standard-dose chemotherapy. J Natl Cancer Inst 90:210-218, 1998

17. Vearncombe KJ, Rolfe $M$, Wright $M$, et al: Predictors of cognitive decline after chemotherapy in breast cancer patients. J Int Neuropsychol Soc 15:951-962, 2009

18. Wefel JS, Saleeba AK, Buzdar AU, et al: Acute and late onset cognitive dysfunction associated with chemotherapy in women with breast cancer. Cancer 116:3348-3356, 2010

19. Weis J, Poppelreuter M, Bartsch $\mathrm{HH}$ : Cognitive deficits as long-term side-effects of adjuvant therapy in breast cancer patients: 'subjective' complaints and 'objective' neuropsychological test results. Psychooncology 18:775-782, 2009

20. Yamada TH, Denburg NL, Beglinger LJ, et al: Neuropsychological outcomes of older breast cancer survivors: cognitive features ten or more years after chemotherapy. J Neuropsychiatry Clin Neurosci 22:48-54, 2010

21. Wefel JS, Vardy J, Ahles T, et al: International Cognition and Cancer Task Force recommendations to harmonise studies of cognitive function in patients with cancer. Lancet Oncol 12:703-708, 2011

22. Castellon SA, Ganz PA, Bower JE, et al: Neurocognitive performance in breast cancer survivors exposed to adjuvant chemotherapy and tamoxifen. J Clin Exp Neuropsychol 26:955-969, 2004

23. Ahles TA, Saykin AJ: Candidate mechanisms for chemotherapy-induced cognitive changes. Nat Rev Cancer 7:192-201, 2007

24. de Ruiter MB, Reneman L, Boogerd W, et al: Late effects of high-dose adjuvant chemotherapy on white and gray matter in breast cancer survivors: Converging results from multimodal magnetic resonance imaging. Human Brain Mapping [epub ahead of print on September 23, 2011]

25. Deprez S, Amant F, Smeets A, et al: Longitudinal assessment of chemotherapy-induced structural changes in cerebral white matter and its correlation with impaired cognitive functioning. J Clin Oncol 30:274-281, 2011

26. Ferguson RJ, McDonald BC, Saykin AJ, et al: Brain structure and function differences in monozy- gotic twins: possible effects of breast cancer chemotherapy. J Clin Oncol 25:3866-3870, 2007

27. Inagaki $M$, Yoshikawa $E$, Matsuoka $Y$, et al: Smaller regional volumes of brain gray and white matter demonstrated in breast cancer survivors exposed to adjuvant chemotherapy. Cancer 109: 146-156, 2007

28. McDonald BC, Conroy SK, Ahles TA, et al: Gray matter reduction associated with systemic chemotherapy for breast cancer: a prospective MRI study. Breast Cancer Res Treat 123:819-828, 2010

29. Saykin AJ, Ahles TA, McDonald BC: Mechanisms of chemotherapy-induced cognitive disorders: neuropsychological, pathophysiological, and neuroimaging perspectives. Semin Clin Neuropsychiatry 8:201-216, 2003

30. Stemmer SM, Stears JC, Burton BS, et al: White matter changes in patients with breast cancer treated with high-dose chemotherapy and autologous bone marrow support. AJNR Am J Neuroradiol 15:1267-1273, 1994

31. Saykin AJ: Altered brain activation following systemic chemotherapy for breast cancer: Interim analysis from a prospective study. J Int Neuropsychol Soc 12:131, 2006

32. Seigers R, Fardell JE: Neurobiological basis of chemotherapy-induced cognitive impairment: A review of rodent research. Neurosci Biobehav Rev 35:729-741, 2011

33. Hofman A, Breteler MM, van Duijn CM, et al: The Rotterdam Study: 2010 objectives and design update. Eur J Epidemiol 24:553-572, 2009

34. Euser SM, Schram MT, Hofman A, et al: Measuring cognitive function with age: The influence of selection by health and survival. Epidemiology 19:440-447, 2008

35. Tiffin J, Asher EJ: The Purdue pegboard; norms and studies of reliability and validity. J Appl Psychol 32:234-247, 1948

36. Folstein MF, Folstein SE, McHugh PR: "Minimental state." A practical method for grading the cognitive state of patients for the clinician. J Psychiatr Res 12:189-198, 1975

37. Kalverboer AF, Deelman BG: De 15woordentest A en B. Groningen, the Netherlands, Academisch Ziekenhuis, 1986

38. Tombaugh TN, Mclntyre NJ: The mini-mental state examination: a comprehensive review. J Am Geriatr Soc 40:922-935, 1992

39. Houx PJ, Jolles J, Vreeling FW: Stroop interference: Aging effects assessed with the Stroop Color-Word Test. Exp Aging Res 19:209-224, 1993

40. Killgore WD, Glahn DC, Casasanto DJ: Development and validation of the Design Organization Test (DOT): A rapid screening instrument for assessing visuospatial ability. J Clin Exp Neuropsychol 27:449-459, 2005 
41. Van der Elst W, Van Boxtel MP, Van Breukelen GJ, et al: Normative data for the Animal, Profession and Letter M Naming verbal fluency tests for Dutch speaking participants and the effects of age, education, and sex. J Int Neuropsychol Soc 12:80 89,2006

42. van der Elst W, van Boxtel MP, van Breukelen GJ, et al: The Letter Digit Substitution Test: normative data for 1,858 healthy participants aged 24-81 from the Maastricht Aging Study (MAAS): Influence of age, education, and sex. J Clin Exp Neuropsycho 28:998-1009, 2006

43. Knight RG, Williams S, McGee R, et al: Psychometric properties of the Centre for Epidemiologic Studies Depression Scale (CES-D) in a sample of women in middle life. Behav Res Ther 35:373380, 1997

44. Radloff LS: The CES-D scale: A self-report depression scale for research in the genetal population. Appl Psychological Measurement 1:385-401, 1977

45. Dietrich J, Monje M, Wefel J, et al: Clinical patterns and biological correlates of cognitive dysfunction associated with cancer therapy. Oncologist 13:1285-1295, 2008

46. Mahalanobis PC: On the generalised distance in statistics. Proceedings of the National Institute of Sciences of India 2:49-55, 1936. http://www. new.dli.ernet.in/rawdataupload/upload/insa/INSA_1/ 20006193_49.pdf

47. Tabachnick BG, Fidell LS: Using Multivariate Statistics (ed 4). Needham Heights, MA, Allyn \& Bacon, 2001, pp 68

48. DeCarlo LT: On the meaning and use of kurtosis. Psychol Met 2:292-307, 1997

49. Follmann D: A simple multivariate test for one-sided alternatives. J Am Stat Assoc 91:854-861, 1996

50. Wefel JS, Lenzi $R$, Theriault $R$, et al: 'Chemobrain' in breast carcinoma?: A prologue. Cancer 101:466-475, 2004

51. Ahles TA, Saykin AJ, McDonald BC, et al: Cognitive function in breast cancer patients prior to adjuvant treatment. Breast Cancer Res Treat 110: 143-152, 2008

52. Ramaiah R, Lam AM: Postoperative cognitive dysfunction in the elderly. Anesthesiol Clin 27:485496, 2009

53. Bender CM, Sereika SM, Berga SL, et al: Cognitive impairment associated with adjuvant ther- apy in breast cancer. Psychooncology 15:422-430, 2006

54. Collins B, Mackenzie J, Stewart A, et al: Cognitive effects of chemotherapy in post-menopausal breast cancer patients 1 year after treatment. Psychooncology 18:134-143, 2009

55. Quesnel C, Savard J, Ivers H: Cognitive impairments associated with breast cancer treatments: Results from a longitudinal study. Breast Cancer Res Treat 116:113-123, 2009

56. Stewart A, Collins B, Mackenzie J, et al: The cognitive effects of adjuvant chemotherapy in early stage breast cancer: A prospective study. Psychooncology 17:122-130, 2008

57. de Jong-van den Berg LT, Faber A, van den Berg PB: HRT use in 2001 and 2004 in the Netherlands: A world of difference. Maturitas 54:193-197, 2006

58. Castellon S, Ganz PA: Neuropsychological studies in breast cancer: in search of chemobrain. Breast Cancer Res Treat 116:125-127, 2009

59. Correa DD, Ahles TA: Neurocognitive changes in cancer survivors. Cancer J 14:396-400, 2008

60. Jenkins $V$, Shilling V, Deutsch $G$, et al: A 3-year prospective study of the effects of adjuvant treatments on cognition in women with early stage breast cancer. Br J Cancer 94:828-834, 2006

61. Schagen SB, Vardy J, Steering Committee of the International Cognition and Cancer Task Force: Cognitive dysfunction in people with cancer. Lancet Oncol 8:852-853, 2007

62. Stewart A, Bielajew C, Collins B, et al: A meta-analysis of the neuropsychological effects of adjuvant chemotherapy treatment in women treated for breast cancer. Clin Neuropsychol 20:76-89, 2006

63. Vardy J, Rourke S, Tannock IF: Evaluation of cognitive function associated with chemotherapy: A review of published studies and recommendations for future research. J Clin Oncol 25:2455-2463, 2007

64. Vardy J, Wefel JS, Ahles T, et al: Cancer and cancer-therapy related cognitive dysfunction: An international perspective from the Venice cognitive workshop. Ann Oncol 19:623-629, 2008

65. Wefel JS, Witgert ME, Meyers CA: Neuropsychological sequelae of non-central nervous system cancer and cancer therapy. Neuropsychol Rev 18: 121-131, 2008

66. Dugdale AE, Chandler D, Jeffery H: Rapid repeated finger tapping. Aust Paediatr J 16:175-176, 1980
67. Leslie SC, Davidson RJ, Batey OB: Purdue pegboard performance of disabled and normal readers: unimanual versus bimanual differences. Brain Lang 24:359-369, 1985

68. Ouimet LA, Stewart A, Collins B, et al: Measuring neuropsychological change following breast cancer treatment: An analysis of statistical models. J Clin Exp Neuropsychol 31:73-89, 2009

69. Schagen SB, Muller MJ, Boogerd W, et al: Late effects of adjuvant chemotherapy on cognitive function: A follow-up study in breast cancer patients. Ann Oncol 13:1387-1397, 2002

70. Schagen SB, van Dam FS, Muller MJ, et al: Cognitive deficits after postoperative adjuvant chemotherapy for breast carcinoma. Cancer 85:640-650, 1999

71. Kreukels BP, van Dam FS, Ridderinkhof $K R$, et al: Persistent neurocognitive problems after adjuvant chemotherapy for breast cancer. Clin Breast Cancer 8:80-87, 2008

72. Briones TL, Woods J: Chemotherapy-induced cognitive impairment is associated with decreases in cell proliferation and histone modifications. BMC Neurosci 12:124, 2011

73. Reiriz $A B$, Reolon GK, Preissler $T$, et al: Cancer chemotherapy and cognitive function in rodent models: Memory impairment induced by cyclophosphamide in mice. Clin Cancer Res 12:5000; author reply 5000-5001, 2006

74. Seigers $R$, Schagen SB, Beerling $W$, et al: Long-lasting suppression of hippocampal cell proliferation and impaired cognitive performance by methotrexate in the rat. Behav Brain Res 186:168175,2008

75. Seigers R, Schagen SB, Coppens CM, et al: Methotrexate decreases hippocampal cell proliferation and induces memory deficits in rats. Behav Brain Res 201:279-284, 2009

76. Winocur G, Vardy J, Binns MA, et al: The effects of the anti-cancer drugs, methotrexate and 5 -fluorouracil, on cognitive function in mice. Pharmacol Biochem Behav 85:66-75, 2006

77. Early Breast Cancer Trialists' Collaborative Group (EBCTCG): Effects of chemotherapy and hormonal therapy for early breast cancer on recurrence and 15-year survival: An overview of the randomised trials. Lancet 365:1687-1717, 2005

78. Levine MN, Whelan T: Adjuvant chemotherapy for breast cancer: 30 years later. N Engl J Med 355:1920-1922, 2006 